\title{
Exploitation of agro industrial wastes as immobilization carrier for solid-state fermentation
}

\author{
María C. Orzua ${ }^{a}$, Solange I. Mussatto ${ }^{\mathrm{b}, *}$, Juan C. Contreras-Esquivel ${ }^{\mathrm{a}}$, \\ Raul Rodriguez ${ }^{\text {, }}$, Heliodoro de la Garza ${ }^{a}$, José A. Teixeira ${ }^{\mathrm{b}}$, \\ Cristóbal N. Aguilar ${ }^{\mathrm{a}}$ \\ a Food Research Department, School of Chemistry, Universidad Autónoma de Coahuila, Saltillo, MX-25000 Coahuila, Mexico \\ ${ }^{\mathrm{b}}$ Institute for Biotechnology and Bioengineering (IBB), Centre of Biological Engineering, University of Minho, Campus de Gualtar, 4710-057 Braga, Portugal
}

\section{A R T I C L E I N F O}

\section{Article history:}

Received 19 December 2008

Received in revised form 2 February 2009

Accepted 4 February 2009

\section{Keywords:}

Agro industrial

Wastes

Aspergillus

Immobilization

Solid-sate fermentation

\begin{abstract}
A B S T R A C T
Ten agro industrial wastes were assessed for their suitability as fungus immobilization carrier for solid-state fermentation (SSF). The wastes included creosote bush leaves (Larrea tridentata), variegated Caribbean agave (Agave lechuguilla), lemon peel (Citrus aurantifolia), orange peel (Citrus sinensis), apple pomace (Malus domestica), pistachio shell (Pistacia vera), wheat bran (Triticum spp.), coconut husk (Cocos nucífera), pecan nutshell (Carya illinoinensis), and bean residues (Phaseolus vulgaris). All of them were physical-chemically and microbiologically characterized. Physical-chemical tests consisted in the determination of the critical humidity point and the water absorption index; while the microbiological tests were based on the evaluation of Aspergillus niger Aa-20 growth rate in such materials. The study pointed out that coconut husk, apple pomace, lemon and orange peels were the materials of greater potential for use as immobilization carrier in SSF, since they have high water absorption capacity, and allowed good microorganism growth rate. This result is of significant interest due to the low cost and abundant availability of such wastes.
\end{abstract}

(c) 2009 Elsevier B.V. All rights reserved.

\section{Introduction}

The worldwide food, agricultural and forestry industries produce annually large volumes of wastes, which cause a serious disposal problem (Rodríguez-Couto, 2008). Some examples of these wastes include the bagasse and peels generated in the beverages and juice industries, coffee pulp obtained in the coffee industry, and husks from the cereal industries. Most of these residues have a nutritional potential, and therefore they are receiving greater attention in terms of quality control and have been classified as agro industrial by-products (Graminha et al., 2008). In the last years, academic and industrial researchers are putting more and more effort to reduce the amount of these wastes by finding alternative uses. Due to the composition rich in sugars, which due to their organic nature are easily assimilated by the microorganisms; they could be appropriate for use as raw materials in the production of industrially relevant compounds under solid-state fermentation (SSF) conditions (Rodríguez-Couto, 2008). In fact, SSF has emerged as an appropriate technology for the management of agro indus-

\footnotetext{
* Corresponding author. Tel.: +351 253 604400x605413; fax: +351 253678986 . E-mail addresses: solange@deb.uminho.pt, solangemussatto@hotmail.com (S.I. Mussatto).
}

trial residues and for their value addition (Bhanu Prakash et al., 2008).

SSF is defined as the growth of microorganisms on moistened solid substrate, in which enough moisture is present to maintain microbial growth and metabolism, but there is no free-moving water (Rahardjo et al., 2006). Selection of a suitable microorganism is one of the most important stages in SSF. Aspergillus niger, for example, is a microorganism able to produce as many as 19 types of enzymes and several other value added compounds, such as citric acid and alcohols, by SSF of agro industrial residues (Schuster et al., 2002; Rodríguez-Couto, 2008). Therefore, it has been used in many SSF studies. Besides the importance of using a suitable microorganism, the development of an efficient SSF process depends on the selection of an appropriate solid substrate. The food, agricultural and forestry industries produce large volumes of wastes that can be used as raw materials under SSF conditions. Example of them include sweet potato residue, corn cob, cassava bagasse, sugar cane bagasse, wheat bran, rice bran, carob pod, spent brewery grains, among others (RodríguezCouto, 2008). Previous to the material use in SSF it is of great importance to determine its physical-chemical and microbiological characteristics. Two important physical-chemical parameters include the water absorption index (WAI) and the critical humidity point (CHP) (Robledo et al., 2008). Microbiologically, it is 


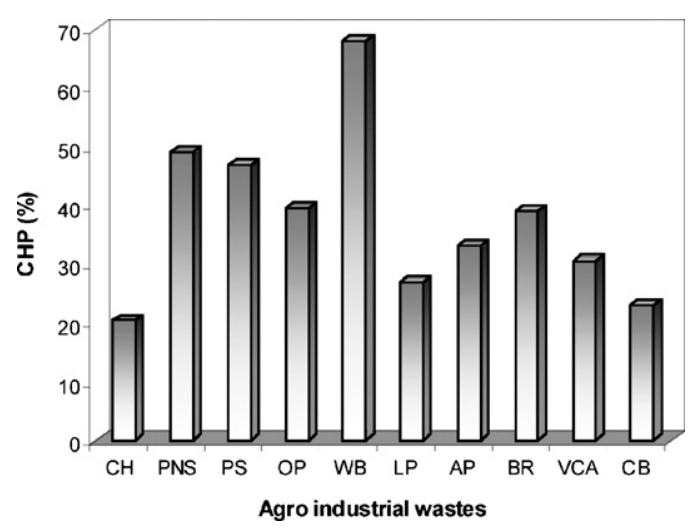

Fig. 1. Critical humidity point (CHP) of the agro industrial wastes: coconut husk $(\mathrm{CH})$, pecan nutshell (PNS), pistachio shell (PS), orange peel (OP), wheat bran (WB), lemon peel (LP), apple pomace (AP), bean residues (BR), variegated Caribbean agave (VCA), and creosote bush leaves (CB).

important to evaluate the microorganism growth rate into the material.

According to Raimbault (1998) to be used as carrier in SSF the material must attain several requisites, including: (a) to be a solid porous matrix which can be biodegradable or not, but with a large surface area per unit volume, in the range of $10^{3}$ to $10^{6} \mathrm{~m}^{2} / \mathrm{cm}^{3}$, for a ready microbial growth on the solid/gas interface; (b) its matrix should absorb water amounting one or several times its dry weight with a relatively high water activity on the solid/gas interface in order to allow high rates of biochemical processes; (c) the air mixture of oxygen with other gases and aerosols should flow under a relatively low pressure and mix the fermenting mash; (d) the solid/gas interface should be a good habitat for the fast development of specific cultures of moulds, yeasts or bacteria, either in pure or mixed cultures; (e) the mechanical properties of the solid matrix should stand compression or gentle stirring, as required for a given fermentation process. This requires small granular or fibrous particles, which do not tend to break or stick to each other; (f) the solid matrix should not be contaminated by inhibitors of microbial activities and should be able to absorb or contain available microbial foodstuffs such as carbohydrates (cellulose, starch and sugars) nitrogen sources (ammonia, urea and peptides) and mineral salts.

Considering the requirements above mentioned the present study deals with the evaluation of the potential of different agro industrial wastes for use as immobilization carrier in SSF. The

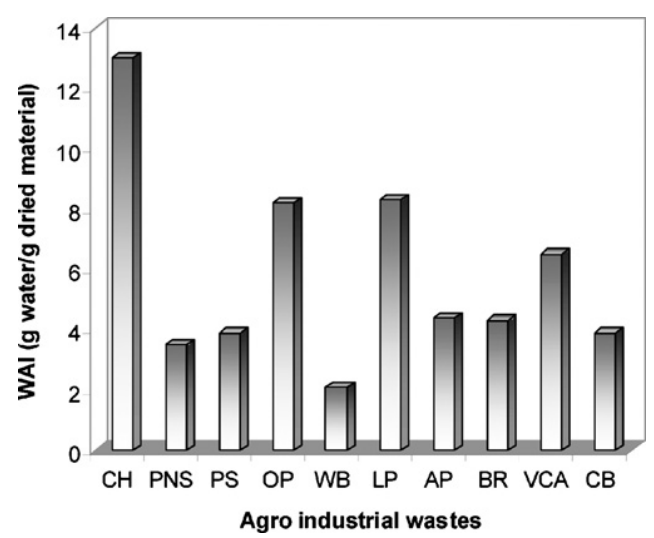

Fig. 2. Water absorption index (WAI) of the agro industrial wastes: coconut husk $(\mathrm{CH})$, pecan nutshell (PNS), pistachio shell (PS), orange peel (OP), wheat bran (WB), lemon peel (LP), apple pomace (AP), bean residues (BR), variegated Caribbean agave (VCA), and creosote bush leaves (CB).

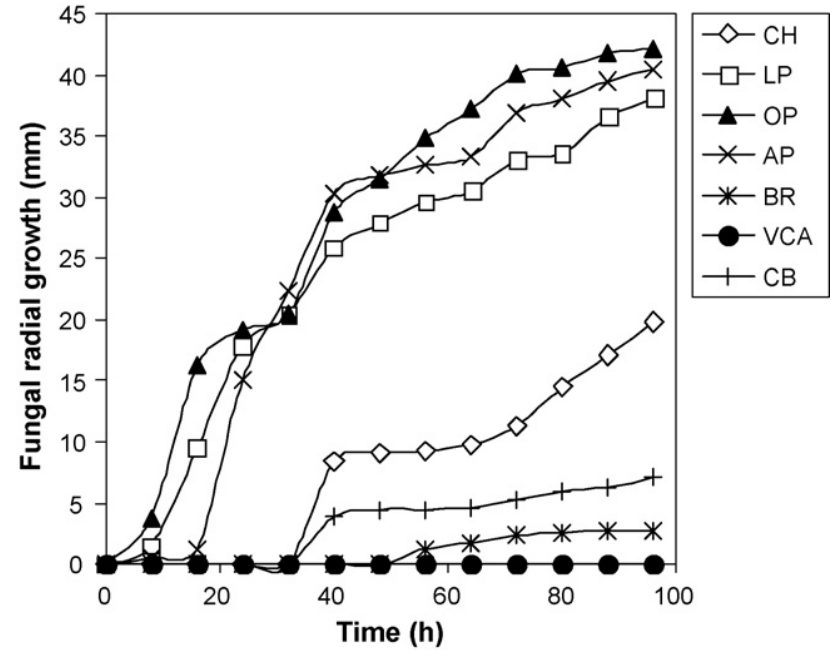

Fig. 3. Aspergillus niger Aa-20 growth by solid-state cultivation in different agro industrial wastes: coconut husk (CH), orange peel (OP), lemon peel (LP), apple pomace (AP), bean residues (BR), variegated Caribbean agave (VCA), and creosote bush leaves $(\mathrm{CB})$.

physical-chemical properties (WAI and CHP), and the ability of $A$. niger Aa-20 to colonize such materials were used as parameters to select the wastes that could be successfully reused in SSF.

\section{Materials and methods}

\subsection{Materials preparation and physical-chemical characterization}

The agro industrial wastes used in this study were derived from Mexican local regions and included creosote bush leaves (Larrea tridentata), variegated Caribbean agave (Agave lechuguilla), lemon peel (Citrus aurantifolia), orange peel (Citrus sinensis), apple pomace (Malus domestica), pistachio shell (Pistacia vera), wheat bran (Triticum spp.), coconut husk (Cocos nucífera), pecan nutshell (Carya illinoinensis), and bean residues (Phaseolus vulgaris). Some of them, namely the creosote bush leaves, lemon peel, orange peel and apple pomace required a previous dehidratation at $55^{\circ} \mathrm{C}$ for $24 \mathrm{~h}$ to be stored until requirement. Pistachio shell, wheat bran, coconut husk, pecan nutshell, and bean residues did not require dehidratation and could be stored as obtained. Variegated Caribean agave was initially washed with water and dried at $55^{\circ} \mathrm{C}$ for $72 \mathrm{~h}$. Subsequently, all the materials were crushed and only particles with size of approximately $50 \mu \mathrm{m}$ were used in the experiments.

After preparation, the materials were physical-chemically characterized. Their water absorption index (WAI) was determined using the method of Anderson et al. (1969). Briefly, the sample $(1.25 \mathrm{~g})$ was suspended in $15 \mathrm{ml}$ of distilled water in a tared $50 \mathrm{ml}$ centrifuge tube. The slurry was stirred with a glass rod for $1 \mathrm{~min}$ at room temperature $\left(25^{\circ} \mathrm{C}\right)$ and centrifuged at $3000 \times g$ and $25^{\circ} \mathrm{C}$ for $10 \mathrm{~min}$. The supernatant was discarded, and the WAI was calculated from the weight of the remaining gel and expressed as g gel/g dry weight. The critical humidity point (CHP) was estimated by adding $1 \mathrm{~g}$ of sample in a thermo-balance at $120^{\circ} \mathrm{C}$ for $60 \mathrm{~min}$ (AOAC, 1980). The CHP was calculated after estimative of the dry rate during the dehidratation kinetic of each material. Subsequently, such velocities were related to the amount of water removed with time.

\subsection{Microbiological tests}

The fungus strain A. niger Aa-20 (IRD-UAMI (Research Institute of Development, France and Metropolitan Autonomous University, 
Table 1

Effect of the initial glucose concentration in the Aspergillus niger Aa-20 growth rate by solid-state cultivation in different agro industrial wastes.

\begin{tabular}{|c|c|c|c|c|}
\hline \multirow[t]{2}{*}{ Initial glucose concentration (g/l) } & \multicolumn{4}{|c|}{ Fungal radial growth rate $(\mathrm{mm} / \mathrm{h})$} \\
\hline & Orange peel & Lemon peel & Apple pomace & Coconut husk \\
\hline 12.5 & 0.25 & 0.17 & 0.22 & 0.22 \\
\hline 25.0 & 0.44 & 0.39 & 0.47 & 0.23 \\
\hline 50.0 & 0.20 & 0.09 & 0.54 & 0.24 \\
\hline 100.0 & 0.23 & 0.15 & 0.34 & 0.25 \\
\hline
\end{tabular}

Mexico) collection) was the microorganism used in the experiments. The strain was maintained at $-20^{\circ} \mathrm{C}$ in a crioprotector medium containing glycerol-skimmed milk. For inoculum preparation, the spores of $A$. niger Aa-20 were inoculated in $250 \mathrm{ml}$ Erlenmeyer flasks containing $50 \mathrm{ml}$ of potato dextrose agar (PDA) medium, and maintained at $30^{\circ} \mathrm{C}$ for 5 days. After this period, the spores were scrapped down from the PDA with a sterilized solution of $0.1 \%(\mathrm{w} / \mathrm{v})$ Tween-80, and counted in a Neubauer chamber.

The assays for determination of the microorganism growth rate were performed in Petri dishes, based on the methodology described by Robledo et al. (2008). The material carrier was impregnated with glucose $(25 \mathrm{~g} / \mathrm{l})$ and the medium humidity was adjusted to $70 \%$. In the sequence, the centre of the dishes was inoculated with a spore suspension containing around $2 \times 10^{7}$ spores $/ \mathrm{ml}$. The time required to completely cover all material in Petri dishes was monitored and the fungus growth rate was determined and expressed as $\mathrm{mm} / \mathrm{h}$. To verify the influence of the initial substrate concentration on the microorganism growth rate, assays were also performed under the same cultivation conditions described above, but varying the initial glucose concentration from 12.5 to $100 \mathrm{~g} / \mathrm{l}$.

\section{Results and discussion}

\subsection{Physical-chemical characterization}

In SSF processes, the microorganisms are grown on porous solid materials generally near-absence of free water in the system. According to Lonsane et al. (1985) for an SSF process be efficient, the substrate must contain enough moisture to simulate the fermentation reaction occurring in nature. Since biological activity ceases below a moisture content of about $12 \%$, this establishes the lower humidity limit at which SSF can take place (Nigam and Singh, 1994). The upper limit is a function of absorbency and hence moisture content varies with the substrate material type. In general, the water content in SSF may range from 30 to almost $80 \%$, depending on the material (Oriol et al., 1988). For this reason, materials with very elevated humidity contents can not be very suitable for use in SSF. The ideal would be having materials with low water content so that the optimum moisture level can be easily adjusted according to the microorganism specie to be used. When water is made available in higher quantity than what is optimally required, the productivity of the process is significantly affected because the microorganism growth and the physical-chemical properties of the solids depend and vary with moisture available to them (Lonsane et al., 1985; Oriol et al., 1988; Bhanu Prakash et al., 2008).

Due to the importance of having materials with low water contents, the primary objective of this work was to check the physical-chemical properties of the agro industrial wastes, namely the CHP and WAI. CHP represents the quantity of water linked to the support, which cannot be employed by the microorganism (Robledo et al., 2008). Moo-Young et al. (1983) recommended a 40\% CHP maximum limit for $A$. niger strains in solid state cultures, due to the need for modification of the moisture content in relation to the absorbed media. Fig. 1 shows the CHP values obtained in the present work to each waste. Among the 10 evaluated materials, only 3 presented
CHP values higher than $40 \%$, including pecan nutshell, pistachio shell and wheat bran.

The WAI indicates the quantity of water that can be absorbed by the support. Materials with high WAI are preferred for SSF since their moisture content can be modified during the solid state culturing (Robledo et al., 2008). Coconut husk, lemon and orange peels were the materials with higher water absorption capacity, whereas wheat bran, pistachio shell and pecan nutshells gave the lowest WAI values (Fig. 2). By analyzing the CHP and WAI results it was thus concluded that pecan nutshells, wheat bran and pistachio shell are not suitable to be used as substrate in SSF. They were thus excluded and only the remaining materials were evaluated in the subsequent microbiological tests.

\subsection{Microbiological tests}

Many microorganisms including fungi, bacteria and yeast can grow on solid substrates in SSF systems. Filamentous fungi are the most widely exploited because of their ability to grow in complex solid substrates even in the absence of free water (Nigam and Singh, 1994; Bhanu Prakash et al., 2008). So, in the present work, the previously selected agro industrial wastes were submitted to microbiological testes, which consisted in the cultivation of $A$. niger strain, and evaluation of the microorganism growth into the materials. Fig. 3 shows the time course of fungus growth in the different materials. It can be noted that $A$. niger had a short lag phase when cultivated in orange peel, and the growth rate was the highest when compared with the other tested materials. The microorganism had also good growth when cultivated in apple pomace and lemon peel, but its development was slower than in orange peel, although at the cultivation end it had totally invaded the carrier. As a whole, apple pomace, lemon and orange peels, mainly the last one, detached among the other materials being the best carriers for SSF. The microbiological test also revealed the unsuitability of three wastes for use as carrier during SSF, namely the variegated Caribbean agave, where the microorganism was unable to growth; the bean residues, where the microorganism growth rate was very slow; and the creosote bush leaves, where the fungus slowly grew and did not invade totally the carrier. Finally, from the 10 agro industrial wastes evaluated in the present work, 4 of them showed great potential to be used in SSF, which included coconut husk, apple pomace, lemon and orange peels.

Table 1 shows the fungal radial growth rate $(\mathrm{mm} / \mathrm{h})$ in these four different materials, under different initial glucose concentrations. It can be noted that the initial substrate concentration strongly affected the fungus growth rate, except in coconut husk, where did not occur significant differences with the variation in the glucose content. In the citrus wastes, glucose concentrations higher than $25 \mathrm{~g} / 1$ affected the microorganism growth, while for apple pomace, glucose concentrations higher than $50 \mathrm{~g} / \mathrm{l}$ reduced the fungus growth rate.

\section{Conclusions}

Based on physical-chemical and microbiological tests it could be concluded that among the 10 agro industrial wastes evaluated, 
4 of them, namely the apple pomace, lemon peel, orange peel, and coconut husk have great potential to be successfully used as immobilization carrier in SSF, for the production of industrially relevant metabolites. Such use would be an interesting alternative to add value to these residues besides to be of great economical advantage and an environmental-friendly way for waste management. Considerations must only be done regarding the initial glucose concentration, which if higher than $25 \mathrm{~g} / \mathrm{l}$ affects the microorganism growth rate in lemon and orange peels, whereas apple pomace values higher than $50 \mathrm{~g} / \mathrm{l}$ affect the microorganism performance. These facts should be taken into account when formulating a fermentation medium from these substrates.

\section{Acknowledgement}

The authors gratefully thank the financial support of the Mexican Council of Science and Technology (project: CONACYT-FOMIX Coahuila).

\section{References}

Anderson, R.A., Conway, H.F., Pfeifer, V.F., Griffin, E., 1969. Gelatinization of corn grits by roll and extrusion cooking. Cereal Sci. Today 14, 11-12.

Association of Official Analytical Chemists (AOAC), 1980. In: Horwitz, W. (Ed.), Official Methods of Analysis of the Association of Official Agriculture Chemistry. AOAC, Washington, DC
Bhanu Prakash, G.V.S., Padmaja, V., Siva Kiran, R.R., 2008. Statistical optimization of process variabes for the large-scale production of Metarhizium anisopliae conidiospores in solid-state fermentation. Bioresour. Technol. 99, 1530-1537.

Graminha, E.B.N., Gonçalves, A.Z.L., Pirota, R.D.P.B., Balsalobre, M.A.A., da Silva, R., Gomes, E., 2008. Enzyme production by solid-state fermentation: Application to animal nutrition. Anim. Feed Sci. Technol. 144, 1-22.

Lonsane, B.K., Ghildyal, N.P., Budiatman, S., Ramakrishna, S.V., 1985. Engineering aspects of solid-state fermentation. Enzyme Microb. Technol. 7, $258-265$.

Moo-Young, M., Moreira, A.R., Tengerdy, R.P., 1983. Principles of solid substrate fermentation. The filamentous fungi. In: Smith, J.E., Berry, D.R., Kristiansen, B. (Eds.), Fungal Technology, vol. IV. Edward-Arnold, London, pp. 117-143.

Nigam, P., Singh, D., 1994. Solid-state (substrate) fermentation systems and their applications in biotechnology. J. Basic Microbiol. 34, 405-423.

Oriol, E., Raimbault, M., Roussos, S., Viniegra-Gonzáles, G., 1988. Water and water activity in the solid state fermentation of cassava starch by Aspergillus niger. Appl. Microbiol. Biot. 27, 498-503.

Raimbault, M., 1998. General and microbiological aspects of solid substrate fermentation. Electron J. Biotechnol. 1, 174-188.

Rahardjo, Y.S.P., Tramper, J., Rinzema, A., 2006. Modeling conversion and transport phenomena in solid-state fermentation: a review and perspectives. Biotechnol. Adv. 24, 161-179.

Robledo, A., Aguilera-Carbó, A., Rodriguez, R., Martinez, J.L., Garza, Y., Aguilar, C.N., 2008. Ellagic acid production by Aspergillus niger in solid state fermentation of pomegranate residues. J. Ind. Microbiol. Biotechnol. 35, 507-513.

Rodríguez-Couto, S., 2008. Exploitation of biological wastes for the production of value-added products under solid-state fermentation conditions. Biotechnol. J. 3, 859-870.

Schuster, E., Dunn-Coleman, N., Frisvad, J.C., van Dijck, P.W.M., 2002. On the safety of Aspergillus niger-a review. Appl. Microbiol. Biotechnol. 59, 426-435. 